\title{
TWO GENERALIZATIONS OF LANDAU'S INEQUALITY
}

\author{
NiCuşor Minculete
}

\begin{abstract}
Let $\pi(x)$ be the number of prime numbers not exceeding $x$. In the introduction we present some inequalities related to this function; these have been presented in several articles about the Number Theory. In the present paper we obtain two inequalities which generalize Landau's Inequality, $\pi(2 x) \leqslant 2 \pi(x)$ for any integer $x \geqslant 2$. Also, we obtain the inequality $2[x \pi(x)+y \pi(y)]>(x+y) \pi(x+y)$, for all integers $x, y \geqslant 67$, and an inequality which refers to the Hardy and Littlewood conjecture. To demonstrate them, we used the Personal Computer, in order to extend the domain of the variables for which these inequalities are true.
\end{abstract}

Mathematics subject classification (2010): 11A25, 11N05.

Keywords and phrases: Prime number, inequalities, Landau's inequality.

\section{REFERENCES}

[1] G. H. Hardy, J. E. LitTlewood, Some problems of "patitio numerorum" III. Acta Math. 44 (1923), $1-70$.

[2] P. DusarT, These, http://www. unilim.fr/laco/theses/1998.

[3] E. Landau, Handbuch der Lehre von der Verteilung der Primzahlen, Band I., Leipzig, 1909.

[4] D. S. Mitrinović, J. SÁndor, B. Crstici, Handbook of Number Theory, Kluwer Academic Publishers, Dordrecht-Boston-London, 1996.

[5] H. L. Montgomery, R. C. Vaughan, The large sieve, Mathematika 20(1973), 119-134.

[6] L. PANAitopol, AL. GiCA, O introducere in aritmetică şi teoria numerelor, Editura Universităţii Bucureşti, 2001.

[7] L. Panaitopol, On the Inequality $\pi(x) \geqslant \frac{x}{\log x-1}$, An. Univ. Buc. Ser. Mat. XLVII (1998), no. 2, 187-192.

[8] L. Panaitopol, Inequalities Concerning the Function $\pi(x)$. Applications, Acta Aritmetica XCIV. 4, 2000, 373-381.

[9] L. PAnaitopol, Some Generalizations for a Theorem by Landau, Mathematical Inequalities \& Aplications, Vol. 4, Number 3(2001), 327-330.

[10] Rosser, J.B., Schoenfeld, L., Aproximate Formulas for Some Functions of Prime Numbers, Ilinois J. Math 6(1962), 64-94.

[11] J. B. Rosser, L. Schoenfeld, Abstract of scientific communications, in: Intern. Congr. Math. Moscow, Section 3: Theory of numbers, 1966.

[12] A. SCHINZEL, Remarks on the paper "Sur certaines hypotheses concernant les nombres premiers", Acta Arith. 7 (1961), 1-8. 